\title{
Improving Safety of Oil Storage Tanks Operation
}

\author{
L. E. Zemlerub, E. R. Kharasov, V. M. Avdeev \\ Petroleum Faculty of Technology, Samara State Technical University, \\ Samara, Russian Federation \\ E-mail: oaoatt25@mail.ru
}

Received: July 22, 2019

\begin{abstract}
Tank batteries for storage of crude oil and refined products are hazardous industrial facilities. Almost half of the accidents (including fires) occurs at the tank batteries at oil and gas industry. The most effective way to improve safety of facilities operation is to introduce additional functions to the existing automated control systems of technological processes. In this article it is proposed to add to automated control systems of technological processes of tank batteries two new subsystems. First one is the subsystem of bottom water drainage from an oil tank by installing on a siphon crane an analyzer of oil concentration in water. The other one is the subsystem of remote leak detection with receiving information from the gas monitoring sensors installed in the leak detection wells and in the area around the tank. Implementation of this additional subsystems to automated control systems of technological processes will allow to receive timely and reliable information about the status of equipment, to increase the efficiency of control and to ensure trouble-free operation which will significantly enhance the safety and efficiency of tank batteries for storage of crude oil and refined products.
\end{abstract}

Keywords: vertical tank, automated system, technological process, operation safety, bottom water, leak detection

\section{INTRODUCTION}

Tank battery (TB) is an essential part of the oil transportation and storage process and allows to maintain pumping cycle. At the same time, tanks have several specific features.

When such a complex product as a crude oil is taken into the tank it starts to stratify and bottom water (BW) appears during the process of water precipitation. Since crude oil contains sulphur, its compounds and other salts, BW is a dilute solution of sulphuric acid and other compounds that accelerate tank's lower ring corrosion and bottom corrosion.

Precipitation of mechanical impurities and bottom water drainage (BWD) reduces the weight of ballast which results in improving crude oil quality and in increasing net weight percent and profitability of crude oil pipeline transportation because payment between suppliers and recipients of oil are made by net weight.

In the Tank Operation Rules it is stated that after taking oil into the tank it is settled for at least two hours, then BWD is performed, and only after that oil is sampled and quality controlled in metrological laboratory. 
In addition, TB for crude oil and refined products are facilities that present potential environmental hazards. The main source of contamination is steam-and-gas mixture displaced from the tanks when they have been filled and when the product volume increases due to temperature rise from night to day. [1]. Product leakage is also a serious risk, therefore tanks for oil and oil products with a volume of more than $2000 \mathrm{~m} 3$ are equipped with a primary leak detection system. LDS consists of a polyethylene film $1 \mathrm{~mm}$ thick, laid under the bottom of the tank at a depth of $70 \mathrm{~cm}$ and a drainage pipe connected to the leak detection well (Fig. 1) [2-3].

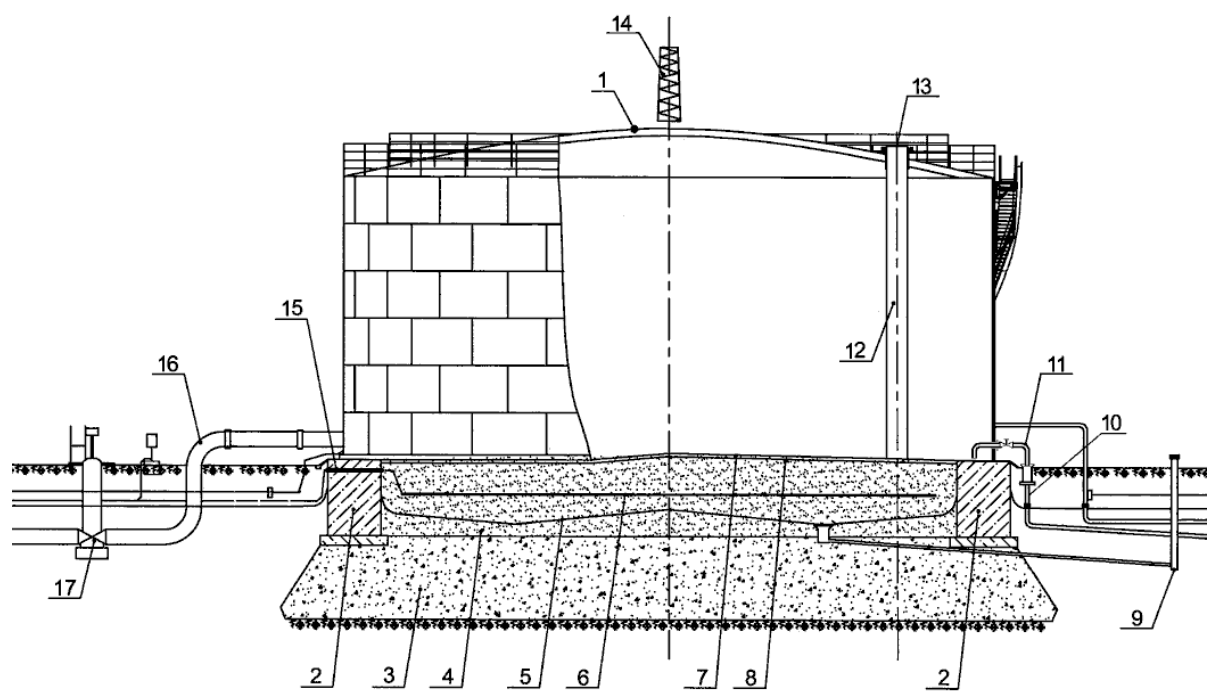

Figure 1. Cross section of the tank: 1 - storage tank; 2 - ring foundation of the tank; 3 - basement of the tank; 4 - sand and gravel mixture; 5 -impervious film; 6 - long anode grounding; 7 - bottom of the tank; 8 hydrophobic layer; 9 - leak detection well; 10 - industrial sewage; 11 - siphon crane; 12 - pontoon guide (pontoon is not shown); 13 - product level measurement system; 14 - lightning protection; 15 - passage of ECP cables through the foundation; 16 - technological pipelines; 17 - pipeline valve

During the operation of TB emissions and leakages are released into the air, waste water and soil. The size of these leaks can be great. This is primarily represented by the fact that they are not detected immediately and it is extremely difficult to prevent them. Therefore, reducing emissions and timely detecting leaks is one of the most important environmental and tank safety operation concerns. $[4,5]$

\section{Automated System OF BotTom WATER DRAinAGE}

These days BW drainage is carried out manually through a siphon crane installed on the tank wall, technical inspection of which should be performed before each process of drainage. The manual method of BWD has following drawbacks: higher labor costs and relatively high losses during a visual control of BWD process. As a result of the search, several patents of automated system of BWD (AS BWD) were found. For instance, the following design was proposed by colleagues of Omsk State Technical University (Fig. 2).

Its peculiarity is that the bottom 2 of the tank 1 is proposed to be made in the form of outward cone. The amount of BW is determined by the position sensor of an interface level "oil-water" 3 , then water is pumped through the pipeline 4 by the pump unit (PU) 6 through the analyzer 5 which determines presence of an oil in a water. When oil appears analyzer sends a signal to the control unit 8 to close the regulator 7. [6] 


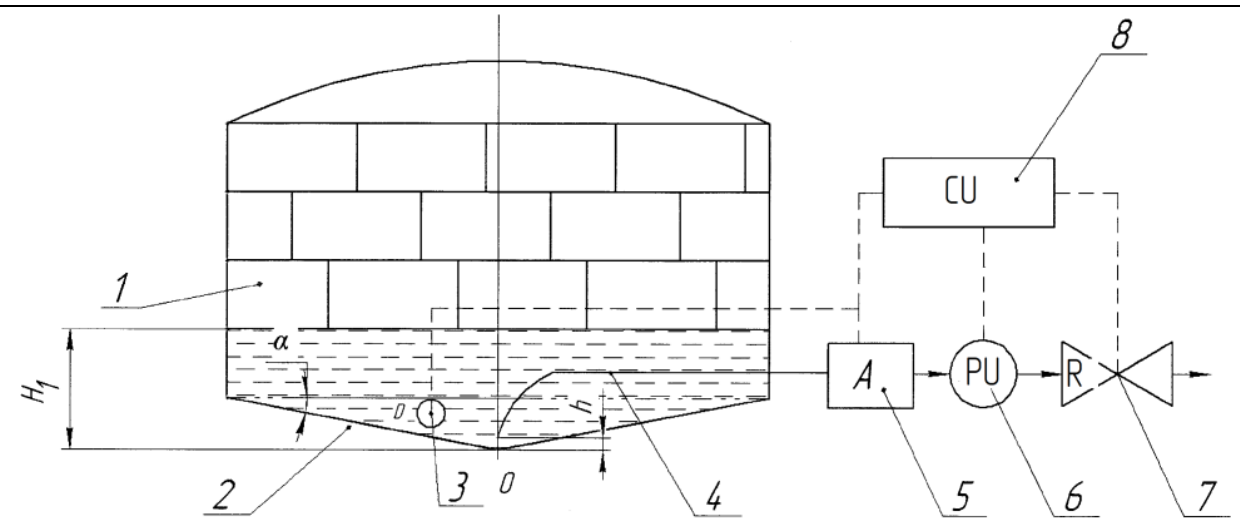

Figure 2. AS BWD of the invention patent number RU $151321 \mathrm{U} 1$

In the design of automatic BWD offered by Saudi company for automation SAFIA determination of oil presence in water is carried out with the help of a device installed on a drainage pipeline. Its operating principal is based on measuring of difference in ultrasound speed in different substances. [7]

In this article it is proposed to use an automated system that reduces crude oil losses during BWD process. The design of AS BWD is similar to that proposed in the patent number RU $151321 \mathrm{U1}$ and includes a siphon to which a ball valve with electric drive and an oil presence alarm are connected. All devices are made in an explosion-proof design.

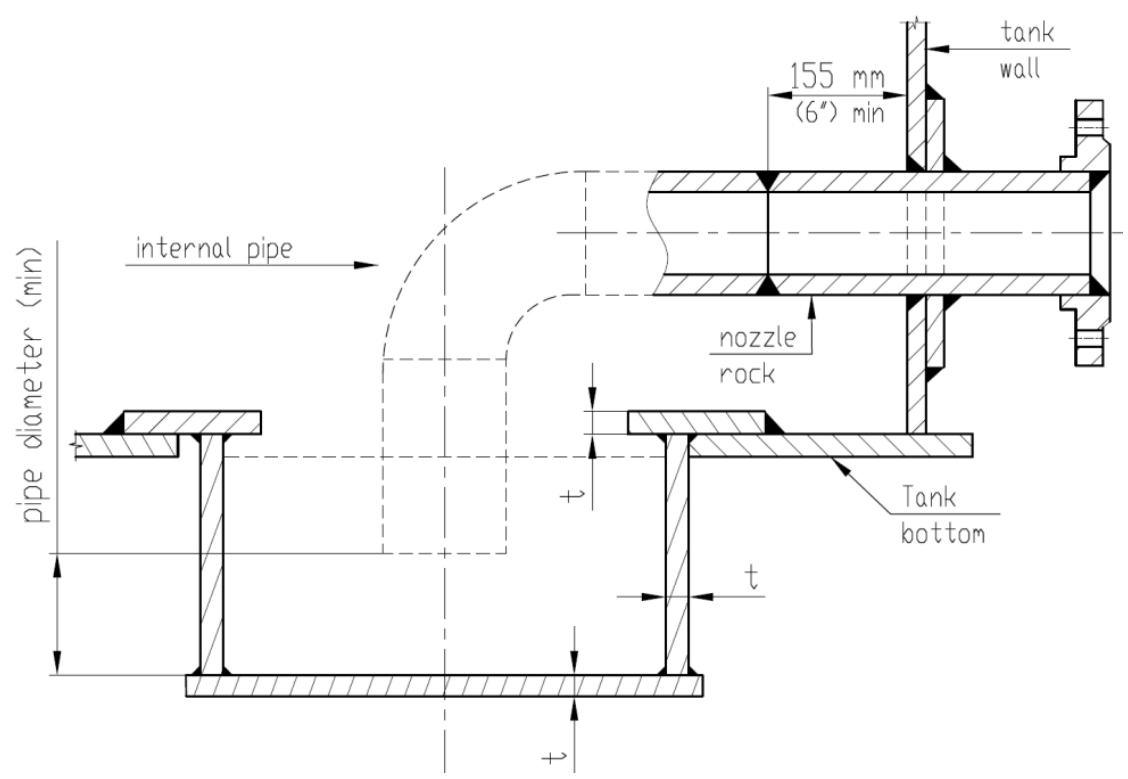

Figure 3. Drain sump on the bottom of the tank

In the design of AS BWD there is no need in using a pump unit since the duration of BWD process is determined by a diameter of syphon cranes and their number which increases proportionally to the increase in a tank volume. The proposal to construct bottom of the tank in the form of outward cone will lead to an increase in stresses and bending moment that occurs when filling the tank in the T-bar welded connection of the wall and bottom which in turn will lead to a decrease in the reliability of the tank. To prevent the inlet of BW into oil a manifold it is enough to provide a small pit (drain sump) on the bottom of the tank with a diameter of $0.5-1.5 \mathrm{~m}$ and to increase the length of siphon crane offset by $3-6 \mathrm{~cm}$ towards 
the tank bottom. For example, in API 650 a water collection pit is proposed to be constructed as shown on Fig. 3. [8]

Selected as an example alarm $\mathrm{CH}-1 \mathrm{~T}$ is designed for continuous monitoring of water quality at explosive facilities, signalization of oil concentration over-limit in water and controlling of executive mechanisms of TP. $\mathrm{CH}-1 \mathrm{~T}$ is a device operating principle of which is based on the effect of fluorescence of oil under ultraviolet irradiation (Fig. 4).

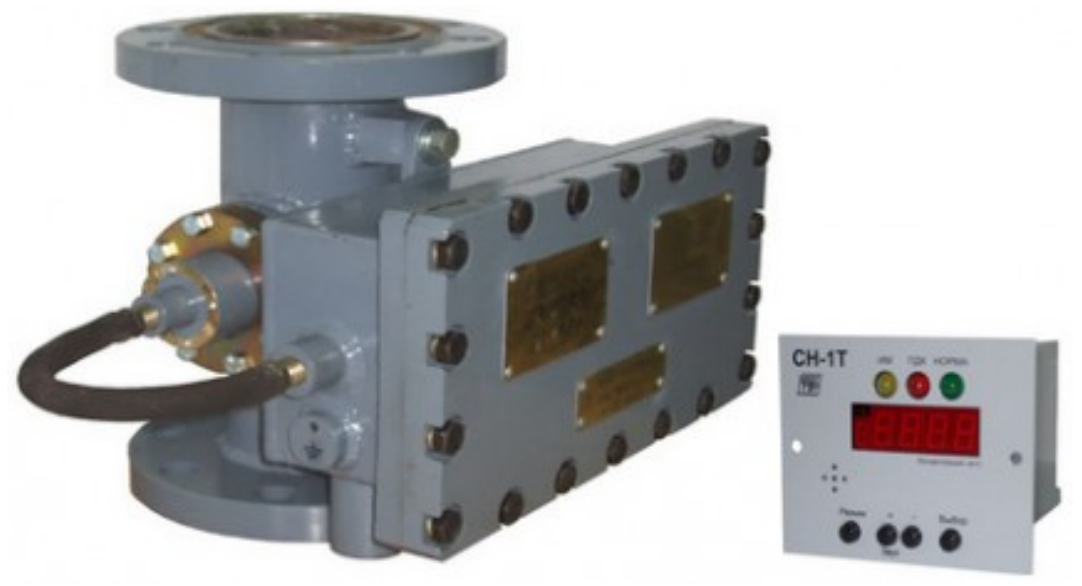

Figure 4. Alarm device $\mathrm{CH}-1 \mathrm{~T}$

BWD is carried out by automatic opening of the ball valve after the time required for water precipitation after taking the crude oil into the tank. During the process of BWD alarm device continuously monitors the concentration of oil in the drainage pipe. When the specified concentration is reached the alarm device will notify about this and send a signal to close the ball valve and stop drainage. The difference of the proposed design lies in its simplicity and in the algorithm of iterative drainage termination when relatively small concentration of oil in water appears, which will lead to a reduction of oil losses.

Since the proposed design is not provided with manual rotation mechanism of a siphon crane as on the tank with manual BWD, it is proposed to heat external part of the system to prevent water freezing at a negative temperature.

The implementation of AS BWD will lead to a reduction in labor costs and elimination of the influence of "human factor" not only during the process of BWD but also during the process of level gaging. It will be required for TB operators to carry out the additional start-up of the system before taking any measurements and sample drawing.

\section{Automated System of REMote LeAK Detection}

Standard ACS TP designed to provide centralized monitor and control of TB consists of the following subsystems:

- system of tank gaging;

- bottom sediments erosion system;

- fire extinguisher system;

- system of gate valves control.

The following parameters are remotely measured and transmitted to local control room:

- oil level in tanks;

- average oil temperature (measured by product layers);

- air temperature in TB. 
At the local control room following parameters are monitored:

- reliability of measured parameters by intervals of allowed values;

- volume of product oil and free capacity;

- position of gate valves of TB process pipelines;

- status of local automatics and communication channels.

ACS TP provides automatic protection against fire and crude oil over fill in tanks. In case of emergency situations automatic light and sound alarming is provided. [9, 10, 11].

In this article it is proposed to install additional sensors and systems to the existing ACS TP to provide following features:

- continuous control of gas-air environment in leak detection wells and in the area around the tank (Fig. 5) [12];

- monitoring of tank cathode protection system (CPS) operation using the potentials obtained from the reference electrodes and signals from corrosion rate sensors located under the tank bottom (Fig. 6) [13, 14, 15].

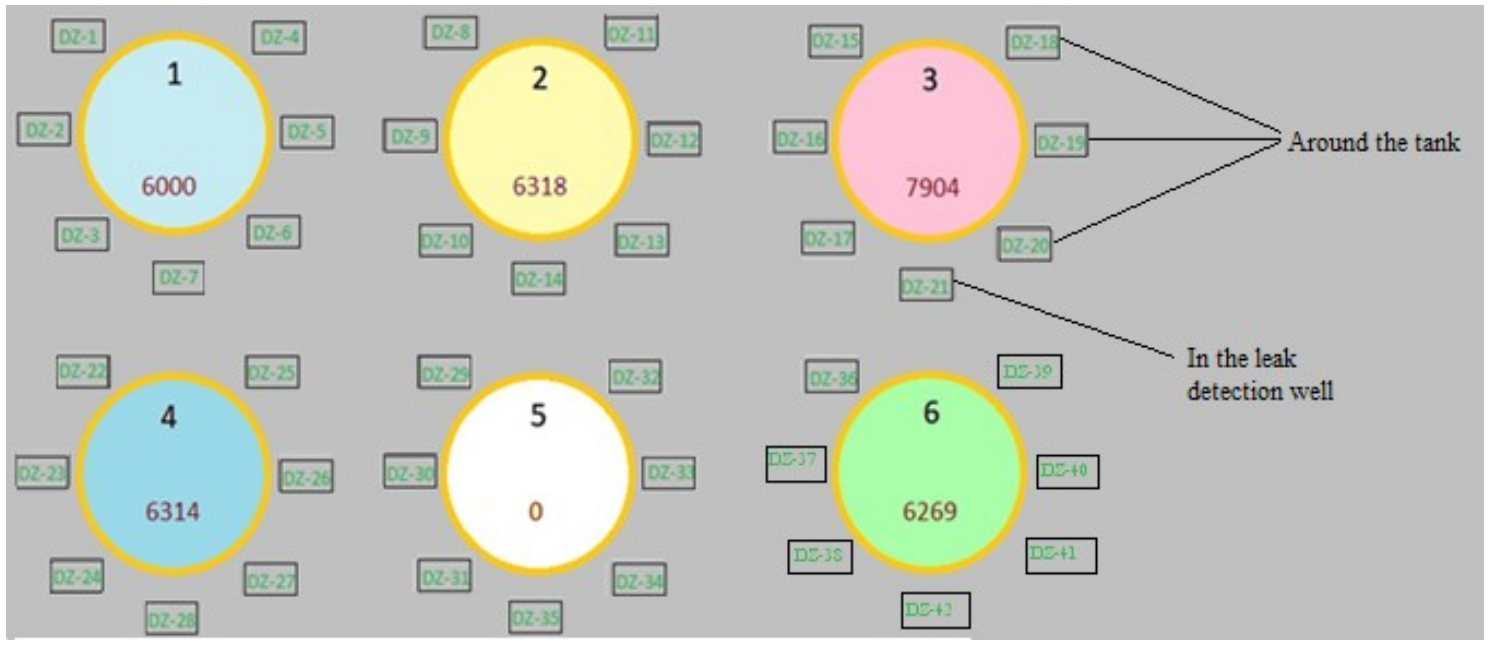

Figure 5. Mnemonic scheme of gas monitoring sensors location at TB

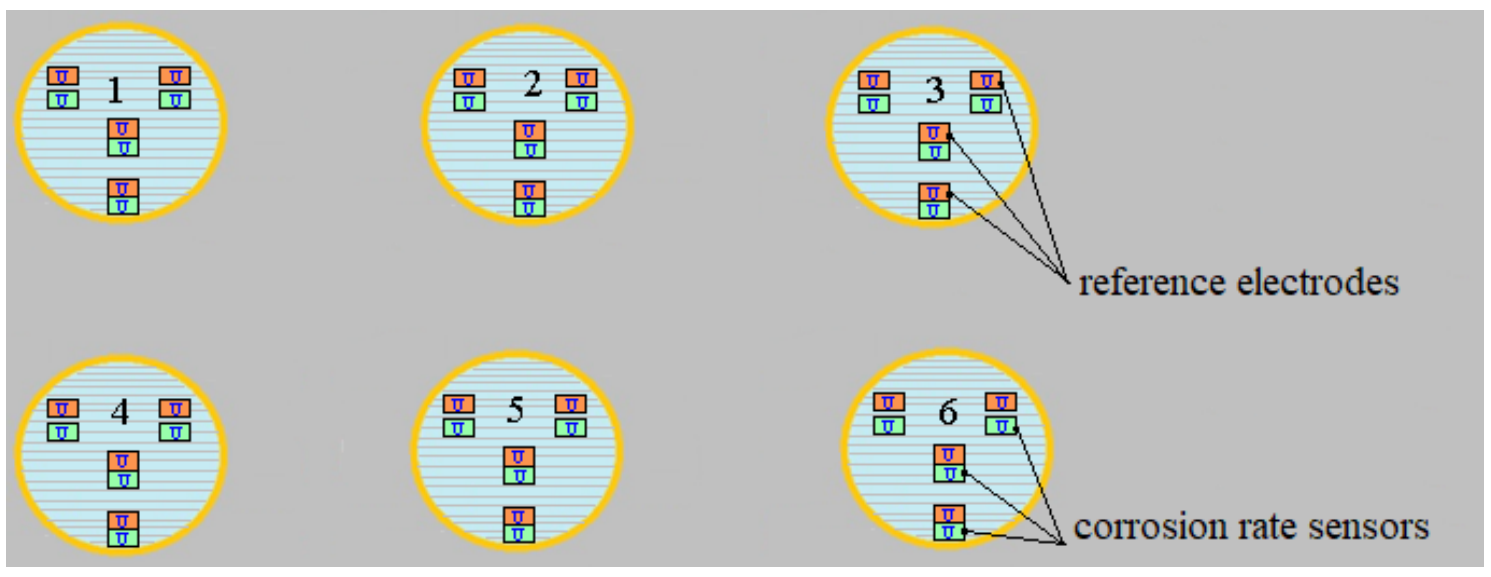

Figure 6. Mnemonic scheme location of reference electrodes and corrosion rate sensors in TB

Information obtained from tank gaging system and additional sensors and systems will provide the development and implementation of combined automated system of remote leak detection (AS RLD) at TB $[16,17]$. 
For the development of the AS RLD it is proposed to use the existing certified software package of ACS TP to which subsystems with following features will be added:

- receiving signals from sensors installed in leak detection wells;

- receiving signals from gas pollution sensors in the area around the tank;

- receiving signals from reference electrodes measuring electric potentials of cathodic protection and corrosion rate sensors installed under the bottom of the tank; screen.

- display of received sporadically arising information on the operator's workstation

In addition to the above mentioned functions AS RLD should perform the analysis of the received information and necessary calculations and separate unreliable data and notify about the approaching accident.

\section{CONCLUSION}

Implementation of AS BWD will lead to a reduction of labor costs, elimination of the "human factor" influence and minimization of oil losses during the process of BWD.

Equipping TB with a system of continuous monitoring of the gas-air environment using sensors installed in the area around the tank and leak detection wells at TB facilities will result in ensuring safe working conditions as well as preventing fires and explosions. [18, 19].

Using the method of adding new functions to existing ACS TP will allow to develop and implement AS RLD for a relatively short period of time and at low cost. Such indicators of AS RLD development can be obtained in the process of technical, informational, mathematical and software development by analogy with the corresponding sections of the current ACS TP [20].

Introduction of additional subsystems of ACS TP will allow to receive timely and reliable information about the status of equipment, to increase the efficiency of control and to ensure trouble-free operation which will significantly enhance the safety and efficiency of TB operation.

\section{REFERENCES}

1. Danilov, V. F., \& Shurygin, V. Y. (2017). Sistema avtomatizirovannogo obnaruzheniya utechek nefteproduktov [System of automatic leak detection of refined products]. Uspekhi sovremennogo estestvoznaniya [The successes of modern science], 2017(11), 63-67. (in Russian).

2. Abbasi, M. H., Benhelal, E., \& Ahmad, A. (2014). Designing an optimal safe layout for a fuel storage tanks farm: Case study of Jaipur oil depot. International Journal of Chemical, Molecular, Nuclear, Materials and Metallurgical Engineering, 2014(8), 147-155. doi: 10.5281/zenodo.1092134

3. Sengupta, A., Gupta, A. K., \& Mishra, I. M. (2011). Engineering layout of fuel tanks in a tank farm. Journal of Loss Prevention in the Process Industries, 24, 568-574. doi: 10.1016/j.jlp.2010.06.016

4. Ibrahim, H. A., \& Syed, H. S. (2018). Hazard analysis of crude oil storage tank farm. International Journal of ChemTech Research, 11(11), 300-308. doi: 10.20902/IJCTR.2018.111132

5. Chang, J. I., \& Lin, Ch.-Ch. (2006). A study of storage tank accidents. Journal of Loss Prevention in the Process Industries, 19, 51-59. doi: 10.1016/j.jlp.2005.05.015

6. Tokarev, V. V., Kucherenko, M. V. \& Pohlebaeva, D. P. (2015). Ustrojstvo dlya udaleniya podtovarnoj vody iz rezervuara [Device for bottom water drainage from a tank]. Ru Patent No. 151321 U1 (in Russian).

7. Safia: Innovative Measureemnts. (n.d.). Automatic Tank Dewatering System. Retrieved from https://www.ksafia.com/automatic-tank-dewatering

8. API standard 650. Welded Steel Tanks for storage of petroleum products. 11th edition, June 2007. 
9. Ickovich, E. L. (2009). Metody racional'noj avtomatizacii proizvodstva [Methods of rational production automation]. Moscow, Russia: Infra-Inzheneriya. (in Russian).

9. Caouette, R., \& Eng, P. (2015). Automation infrastructure upgrades at an oil storage terminal. In: Process Control \& Safety Symposium, 2015. Retrieved from: https:/23.235.204.252/ letico/wp-content/uploads/ 2017/04/TP15PCS073.pdf

10. Sharma, R. K., Gurjar, B. R., Singhal, A. V., Wate, S. R., Ghuge, S. P., \& Agrawal, R. (2015). Automation of emergency response for petroleum oil storage terminals. Safety Science, 72, 262-273. doi: 10.1016/j.ssci.2014.09.019

11. Thompson, J. (2013). Choosing the correct leak detection for tanks. Retrieved from the PetrolPlaza website: https://www.petrolplaza.com/knowledge/2888

12. Bae, J.-H., Ha, T.-H., \& Lee, H.-G. (2003). Development of remote corrosion monitoring and control system for oil tanks by using a high efficiency CP rectifier. IFAC Proceedings Volumes, 36, 951-955. doi: 10.1016/S1474-6670(17)34596-2

13. Meroufel, A., Al Hajri, M., \& Abed, K. (2016). Mitigation of soil-side corrosion on storage tank bottoms in the absence of deficient CP system. NACE $16^{\text {th }}$ Middle East Corrosion Conference \& Exhibition (pp. 113). NACE Paper No. MECCFEB16-7995. Retrieved from: https://www.cortecvci.com/Publications/ Papers/8-MECCFEB16-7995.pdf

14. Welsh, R. A., \& Benefield, J. (2006). Environmental protection through automated remote monitoring of fuel storage tank bottoms using electrical resistance probes. Materials Performance, 45(3), 38-40.

15. Yang, L. (Ed.). (2008). Techniques for corrosion monitoring. Woodhead Publishing.

16. Ali, M., \& Al Beed, A. A. (1998). Above-ground tank bottom corrosion due to inappropriate construction practices and corrosion control using cathodic protection. In: CORROSION 98 (March 22-27, 1998). San Diego, USA: NACE International. Retrieved from: https://www.onepetro.org/conference-paper/NACE98596

17. Hamatdinova, A. V., \& Smorodova, O. V. (2015). Pribornyj kontrol' sostoyaniya gazo-vozdushnoj sredy na predpriyatitah neftepererabotki [Instrumental monitoring of the gas and air environment at oil refineries]. Tekhnologiya tekhnosfernoj bezopasnosti [Technology of technospheric safety], 62, 1-7. (in Russian).

18. Li, S. C. (2004). Oil tank fire statistical analysis. Fire Control Theory Research, 04, 0117.

19. Argyropoulosa, C. D., Christolisa, M. N., Nivolianitou, Z., \& Markatos, N. C. (2012). A hazard assessment methodology for large liquid hydrocarbon fuel tanks. Journal of Loss Prevention in the Process Industries, 25, 329-335. doi: 10.1016/j.jlp.2011.12.003 